\title{
Parameter calibration for the discrete element simulation model of commercial organic fertilizer**
}

\author{
Can Xie ${ }^{1}{ }^{1}$, Jingwei Yang ${ }^{1}$, Baoshuai Wang ${ }^{2}$, Peng Zhuo ${ }^{1}$, Chengsong Li ${ }^{1}$, and Lihong Wang ${ }^{1}(\mathbb{D} *$ \\ ${ }^{1}$ College of Engineering and Technology, Southwest University, Chongqing 400700, China \\ ${ }^{2}$ College of Mechanical and Electrical Engineering, Shihezi University, Shihezi 832000, China
}

Received February 21, 2021; accepted March 8, 2021

\begin{abstract}
The parameters of a discrete element simulation model for commercial organic fertilizer particles were obtained both quickly and accurately, so that the uniformity and stability of the fertilizer discharged from the feeder may be studied using the discrete element simulation method. This study screened out the parameters which significantly influenced the repose angle of the commercial organic fertilizer using the Plackett-Burman test. Then, a model for the quadratic regression response surface of the repose angle $v s$ the parameters was established through a Box-Behnken experiment with the measured repose angle of the fertilizer particles as the optimization index. The optimization results showed that the rolling friction coefficient and static friction coefficient between the fertilizer particles, as well as the optimal simulation parameter for the Johnson-Kendall-Roberts surface energy were $0.056,0.355$ and $0.011 \mathrm{~J} \mathrm{~m}^{-2}$, respectively. A discrete element simulation test was carried out with the optimal simulation parameters, and the repose angle error of the simulation test was found to be $0.40 \%$ relative to that of the physical test, which proved the accuracy and validity of the simulation parameters for the discrete element model of the organic fertilizer. The simulation results may provide the basic parameters for establishing a discrete element model of commercial organic fertilizer particles and investigating the performance of organic fertilizer feeders using the simulation method.

Keywords: commercial organic fertilizer, discrete element, repose angle, parameter calibration, parameters for the particle model
\end{abstract}

*Corresponding author e-mail: 448605310@qq.com

**This work was supported by "Project supported by the special fund for basic scientific research in Central Universities (Project No.: swu019015, 2019-2021)" and "Chongqing technology innovation and application development project (Project No.: cstc2019jscx-msxmx0341, 2019-2021)".

\section{INTRODUCTION}

The application of organic fertilizer can effectively alleviate soil hardening and reduce environmental pollution, which is very important for the sustainable development of agriculture (Dong et al., 2010). With the development of ecological agriculture, the challenge of agricultural non-point source pollution control has resulted in the more widespread application of commercial organic fertilizer (Jiang et al., 2018). Commercial organic fertilizer is different from other fertilizers in terms of friction and flow characteristics due to the differences in moisture and chemical composition (Huang et al., 2017), while the existing feeders for commercial organic fertilizer produce a poor performance.

In the process of fertilization, the discrete element method (DEM) has been widely used to study the interaction of typical bulk materials like soil, seed and fertilizer with agricultural equipment, as well as the relevant movement states (Huang et al., 2016; Liu et al., 2018; Hu et al., 2016; Molenda et al., 2011). In a discrete element simulation analysis, the accuracy of the parameters for the particle material model is the key to the reliability of the simulation (Zhong et al., 2009; Han et al., 2014; Gallego et al., 2020). However, the parameters for contact between materials in

(C) 2021 Institute of Agrophysics, Polish Academy of Sciences 
the discrete element model are difficult to obtain directly through physical experiments. In order to achieve this, many scholars have calibrated the simulation parameters for various agricultural bulk materials through physical experiments combined with simulation experiments (Li et al., 2016; Chen et al., 2013). González-Montellano et al. (2012) directly measured the parameters for some discrete element simulation models of irregular particle materials, such as corn and olive, and found that the error for the direct measurement of the model parameters was very large. Coetzee et al. (2009) carried out shear and confined compression tests on corn particles, calibrated the corresponding friction coefficient and stiffness coefficient, and verified the tests. Wang et al. (2017) used the elastic-plastic contact model to represent the contact model of soil particles, calibrated the parameters to achieve a discrete element model of the soil, and carried out a tyre-soil hardening simulation test for verification. Liu et al. (2016) calibrated a discrete element model for wheat seeds, and found that the repose angle in the simulation test was very close to the measured repose angle. Liu et al. (2018) explored the influence of various parameters on the repose angle with urea granules as the subjects, and found that the error in the simulation results for the calibrated parameters relative to the measured repose angle was only $0.36 \%$. Luo et al. (2018) proposed a method to predict the repose angle through measuring the moisture content of the earthworm manure matrix, and deducing the model parameters through a regression model of the repose angle and other parameters to infer the model parameters through a regression model of the repose angle vs other parameters. Commercial organic fertilizer is different from other agricultural bulk materials in terms of friction and flow characteristics, and therefore, it is necessary to calibrate the parameters to generate a discrete element model of the commercial organic fertilizer particles and thereby establish a discrete element model of the fertilizer, so as to optimize the uniformity and stability of the organic fertilizer feeder using the discrete element method.

This study combined a physical test with a simulation test and screened out the parameters which significantly influence the repose angle of commercial organic fertilizer using the Plackett-Burman test, with the repose angle serving as the response index. Then, a model for the quadratic regression response surface of the repose angle vs the relevant parameters was established through a Box-Behnken experiment with the measured repose angle of the fertilizer particles as the optimization index. Thus, the optimal parameters for the simulation test materials of the organic fertilizer particles were obtained. The results may provide the basic parameters for the establishment of a discrete element model for commercial organic fertilizer particles, as well as aiding in the design and optimization of the performance of fertilizer feeders by means of simulation analysis.

\section{MATERIALS AND METHODS}

The commercial organic fertilizer used in this study is a granular fertilizer made from the stalks of soybean and other biomass, it is produced by the Stanley Company (Name: Soybean 50, Standard: NY525-2012, Organic Matter Content 50\%) (Fig. 1). The commercial organic fertilizer particles selected for the experiment were approximately of spherical shape. A total of 100 commercial organic fertilizer particles were randomly measured with a vernier calliper (accuracy: $0.01 \mathrm{~mm}$ ). The diameter ranged from 2.46 to $4.72 \mathrm{~mm}$ with the average of $3.75 \mathrm{~mm}$ and the standard deviation of 0.438 . The particle diameter was in accordance with the normal distribution with the average particle diameter as the mathematical expectation (Fig. 2).

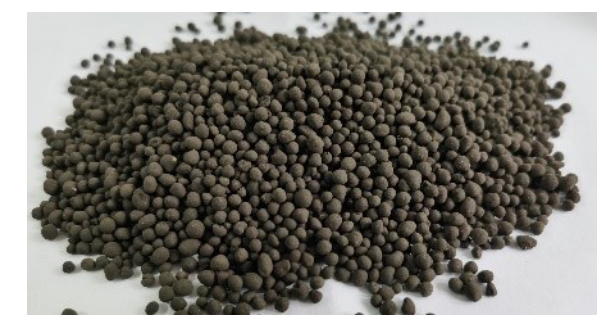

Fig. 1. "Soybean 50" commercial organic fertilizer.

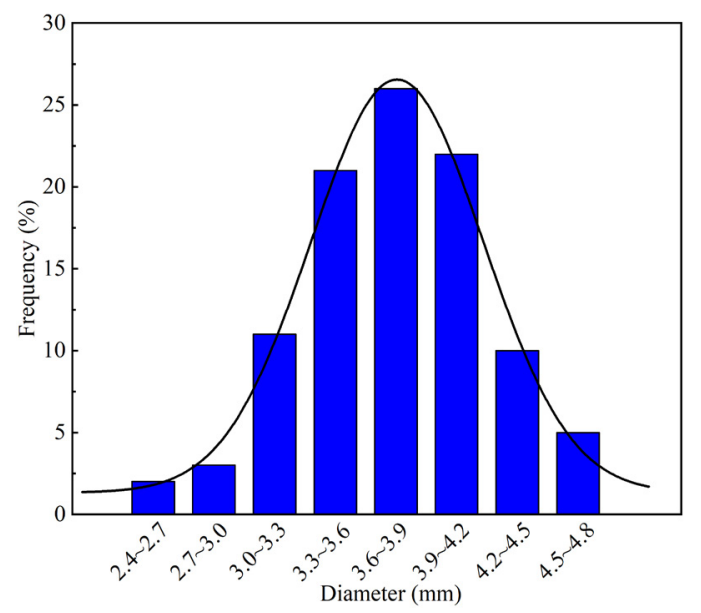

Fig. 2. Grain size distribution of commercial organic fertilizer.

The test method of volume density of fertilizer particles was as following: After measuring the diameter $\Phi$ of each fertilizer particle above, the electronic balance (accuracy: $0.0001 \mathrm{~g}$ ) was used to measure its weight $m$. Then its volume density was calculated as:

$$
\rho=\frac{6 m}{\pi \Phi^{3}} .
$$

The bulk density of fertilizer particles was measured according to the standard: ISO 3944-1992 (Liu et al., 2018). The moisture content of fertilizer particles was measured according to the standard: $G B / T$ 8576-2010 (Wang et al., 2020). The basic material parameters of the commercial organic fertilizer are as shown in Table 1. 
Table 1. Basic material parameters of fertilizer

\begin{tabular}{cccc}
\hline \multirow{2}{*}{$\begin{array}{c}\text { Fertilizer } \\
\text { name }\end{array}$} & \multicolumn{2}{c}{ Density $\left(\mathrm{kg} \mathrm{m}^{-3}\right)$} & \multirow{2}{*}{$\begin{array}{c}\text { Moisture } \\
\text { content }(\%)\end{array}$} \\
\cline { 2 - 3 } & volume & bulk & \\
\hline Soybean 50 & 1280 & 790 & $15.3 \pm 1.2$ \\
\hline
\end{tabular}

The repose angle (AOR) is one of the most important parameters with which to characterize the flow, friction and collision characteristics of bulk materials (Zhao et al., 2009), which may directly affect the uniformity and stability of fertilizer feeders, and is often used for parameter calibration of bulk materials (Ghazavi et al., 2008; Fielke et al., 2013). In this study, the repose angle was measured with a test method for bulk materials as a reference (ISO 4324-1977). The test apparatus consists of the following: 1. Base plate, 2. Support, 3. Funnel, 4. Material tray (Fig. 3). During the test, the fertilizer particles moved slowly from the top of the funnel, excessive impact on the top of the fertilizer heap should be avoided to eliminate overspeed. The fertilizer in the tray forms a conical fertilizer heap for the subsequent determination of the repose angle.

An analysis of the physical test results of the repose angle showed that the external contours for both sides of the fertilizer heap were generally symmetrical. Images of the profiles were captured in order to measure the repose angle of the heap using an image-digital fitting method (Luo et al., 2018; Fadavi et al., 2015). First, an original image (Fig. 4a) was obtained after cropping the photo and removing the redundant background. The original image (Fig. 4a) was subjected to a gray processing technique (Fig. $4 \mathrm{~b}$ ) and also binarization processing (Fig. 4c) based on an image processing program using the Python language, and finally, the boundary profiles were extracted (Fig. 4d). The images for the boundary profile of the fertilizer heap obtained from the test were imported into the numerical analysis and drawing software Origin 2018 for extracting the pixel points of the profiles, which allowed for the determination of the repose angle of the organic fertilizer particles.

Using Origin software, a Gaussian curve was used for a fit analysis on the profiles as shown in the following image (Fig. 5). The Gaussian curve equation for profiles of the fertilizer heap is as follows:

$$
f(x)=y_{0}+\frac{A}{w \sqrt{\frac{\pi}{2}}} e^{-2 \frac{\left(x-x_{c}\right)^{2}}{w^{2}}},
$$

where: $\mathrm{y}_{0}, A, w, x_{c}$ are constants. The acute angle formed by the tangent line at the inflection point and the $\mathrm{X}$-axis of the fitting Eq. (2) is defined as the repose angle of the fertilizer heap. Then, k, the slope at the inflection point of Eq. (2) is calculated as follows:

$$
k= \pm \frac{4 A}{w^{2} \sqrt{2 e \pi}}
$$

then $\theta$ the repose angle, is calculated as follows:

$$
\theta=\arctan |k| .
$$

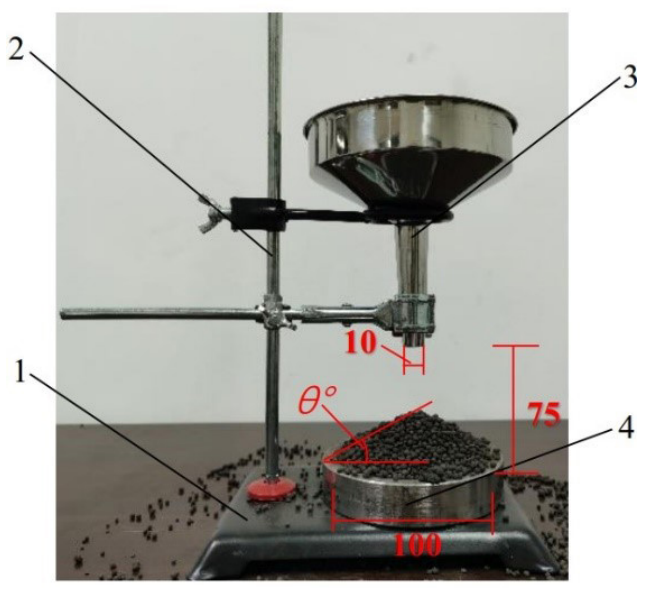

Fig. 3. Test apparatus for determining angle of repose (unit: $\mathrm{mm}$ ): 1 - base plate, 2 - support, 3 - funnel, 4 - material tray.

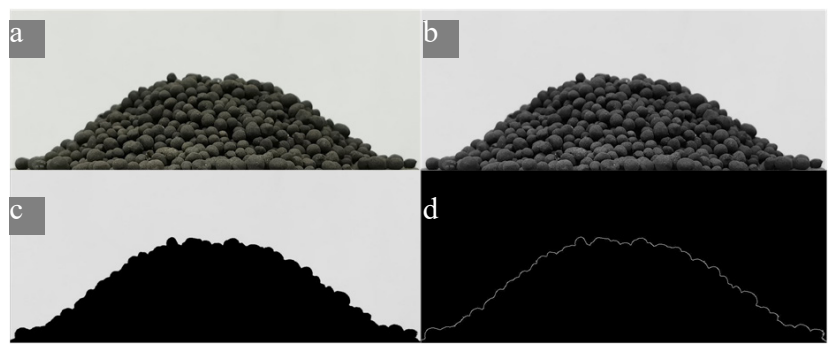

Fig. 4. Process of image processing: $a$ - original image, $b$ - gray processing, $\mathrm{c}$ - binarization, $\mathrm{d}$ - extract contour.

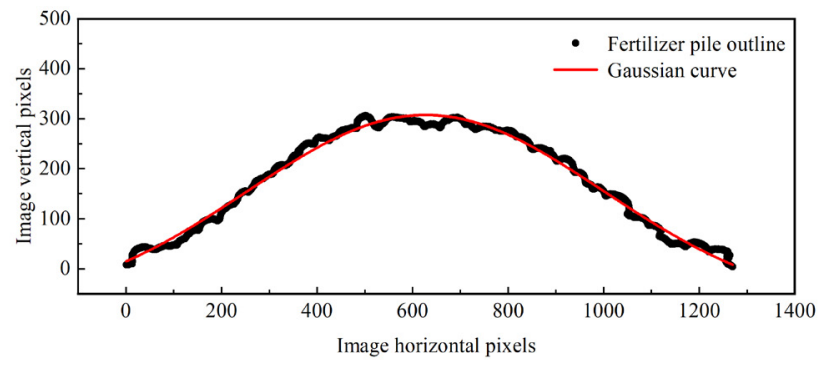

Fig. 5. Fitting image of the external contour of the fertilizer heap.

According to the physical test results for the repose angle of commercial organic fertilizer, the measured repose angle of organic fertilizer particles ranged from 30.57 to $33.60^{\circ}$. The total number of physical tests was 10 , and the average value was $32.05^{\circ}$. In this study, the average repose angle of organic fertilizer particles was selected as the average effective value of the physical test for carrying out the parameter simulation calibration test for organic fertilizer materials.

According to the physical tests, models of the funnel and tray were established in the discrete element analysis software EDEM 2018. The size of the simulation model was consistent with that of the physical test apparatus. According to the range of the fertilizer particle-size distribution, the average diameter of the measured fertilizer 


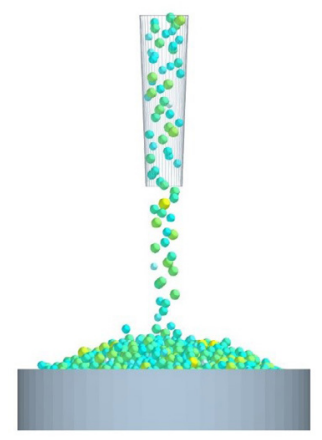

Fig. 6. Discrete element simulation model.

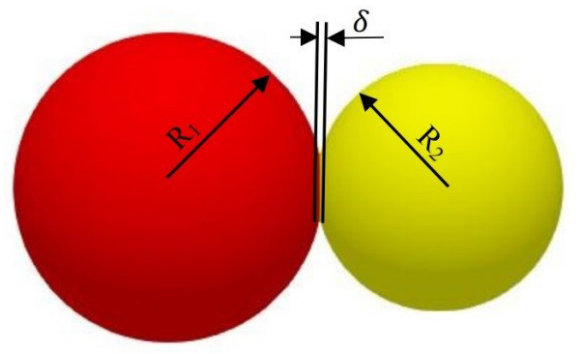

Fig. 7. JKR contact model.

particles, which was $3.75 \mathrm{~mm}$, was selected as the average diameter of the particle model (Fig. 2). In order to make the simulation more precise, based on the rule of particle-size distribution, the diameter variation range of the particles generated by the particle factory was set as the standard normal distribution which satisfied the average value with a standard deviation of $0.1 \mathrm{~mm}$. The maximum diameter was set to 1.2 times the average value, while the minimum diameter was set to 0.7 times the average value. The total number of fertilizer particles used for simulation was 5000 . The discrete element simulation model of organic fertilizer particles is shown in Fig. 6.

In the discrete element simulation, a reasonable contact model is the key to simulating the properties of real organic fertilizer particles, this directly affects the accuracy of the discrete element method for evaluating and optimizing the performance of fertilizer feeders. Hertz-Mindlin with Johnson-Kendall-Roberts contact model (hereinafter referred to as JKR contact model) introduces surface energy into the interaction between particles, which can well simulate the cohesive force of commercial organic fertilizer particles due to water (Fig. 7) (Oleh et al., 2009). The JKR contact model is a cohesive contact model based on Hertz contact theory in combination with JKR theory. It is suitable for systems that determine the influence of van der Waals forces in contact areas and simulate the relevant viscosity, e.g. dry powder or wet particles. It is different from the Hertz-Mindlin contact model, this model calculates its JKR normal elastic force based on $\delta$, the overlap, interaction parameter and $\gamma$, the surface energy:

$$
\begin{gathered}
F_{J K R}=-4 \sqrt{\pi \gamma E^{*}} \alpha^{\frac{3}{2}}+\frac{4 E^{*}}{3 R^{*}} \alpha^{3}, \\
\delta=\frac{\alpha^{2}}{R^{*}}-\sqrt{\frac{4 \pi \gamma \alpha}{E^{*}}},
\end{gathered}
$$

where: $F_{J K R}$ is the normal elastic force $(\mathrm{N}), \alpha$ is the contact circle radius of two particles in contact with each other $(\mathrm{m})$, $\delta$ the overlap $(\mathrm{m}), \gamma$ is the surface energy $\left(\mathrm{N} \mathrm{m}^{-1}\right), E^{*}$ is the equivalent elastic modulus (MPa), $R^{*}$ is the equivalent radius $(\mathrm{m})$. The equivalent elastic modulus and equivalent radius are defined respectively as:

$$
\begin{gathered}
\frac{1}{E^{*}}=\frac{1-v_{i}^{2}}{E_{i}}+\frac{1-v_{j}^{2}}{E_{j}}, \\
\frac{1}{R^{*}}=\frac{1}{R_{i}}+\frac{1}{R_{j}},
\end{gathered}
$$

where: $E_{i}, v_{i}, R_{i}$ and $E_{j}, v_{j}, R_{j}$ are respectively; the elastic modulus, Poisson's ratio and the particle radius of the two particles in contact with each other.

After the repose angle of the fertilizer particles was obtained, the material parameters of the fertilizer particle model were calibrated using a discrete element simulation method. The material parameter ranges of the discrete element model for commercial organic fertilizer were determined based on the relevant literature (Zhang, 2017), the built-in database GEMM of EDEM software and pretest they were as shown in Table 2. The funnel and tray were constructed from steel, with parameters (Ucgul et al., 2015) as follows: Poisson's ratio $=0.3$, density $=7865 \mathrm{~kg}$ $\mathrm{m}^{-3}$ and shear modulus $=7.97 \times 10^{10} \mathrm{~Pa}$. The density of the commercial organic fertilizer particles was $1280 \mathrm{~kg} \mathrm{~m}^{-3}$ (Table 1). The repose angle of the fertilizer heap was measured through the use of the image - digital fitting method. At the end of the simulation, screenshots were taken of the horizontal direction of the fertilizer heap for subsequent processing. Each group of tests was repeated 5 times, so as to obtain the average value.

As with calibrating the parameters of the fertilizer particle simulation model in the simulation test, the key to obtaining optimal simulation parameters of organic fertilizer is to determine the main factors influencing the response value of the repose angle with a sufficient degree of accuracy, explore the influence of the significant factors on the repose angle, and establish a quadratic regression model of significant factors vs repose angles. Therefore, this study is designed to utilize a screening test (Plackett-Burman test) for screening out the test factors that may significantly influence the repose angle. After that, a single factor experiment was conducted to explore the influence of each significant factor on the repose angle, and the range of the optimal simulation parameters for the significant factor was determined by the steepest ascent test. Finally, the quadratic regression model of the repose angle $v s$ significant factors 
Table 2. Simulation model parameters of fertilizer particles

\begin{tabular}{|c|c|c|c|c|c|}
\hline \multicolumn{2}{|l|}{ Parameter } & Test identifier & $\begin{array}{c}\text { Low level } \\
\quad(-1)\end{array}$ & $\begin{array}{c}\text { Central point } \\
(0)\end{array}$ & $\begin{array}{l}\text { High level } \\
\qquad(+1)\end{array}$ \\
\hline \multicolumn{2}{|l|}{ Poisson's ratio } & A & 0.2 & 0.3 & 0.4 \\
\hline \multicolumn{2}{|c|}{ Shear modulus (MPa) } & $\mathrm{B}$ & 50 & 100 & 150 \\
\hline \multirow{3}{*}{$\begin{array}{l}\text { Fertilizer-fertilizer } \\
\text { coefficient of }\end{array}$} & restitution & $\mathrm{C}$ & 0.35 & 0.55 & 0.75 \\
\hline & static friction & $\mathrm{D}$ & 0.2 & 0.6 & 1 \\
\hline & rolling friction & $\mathrm{E}$ & 0 & 0.125 & 0.25 \\
\hline \multirow{3}{*}{$\begin{array}{l}\text { Fertilizer-steel } \\
\text { coefficient of }\end{array}$} & restitution & $\mathrm{F}$ & 0.4 & 0.6 & 0.8 \\
\hline & static friction & G & 0.3 & 0.45 & 0.6 \\
\hline & rolling friction & $\mathrm{H}$ & 0 & 0.125 & 0.25 \\
\hline \multicolumn{2}{|c|}{$\mathrm{JKR}$ surface energy $\left(\mathrm{J} \mathrm{m}^{-2}\right)$} & I & 0 & 0.02 & 0.04 \\
\hline
\end{tabular}

was established by a response surface test (Box-Behnken test), and the optimal simulation parameters were obtained through solving the quadratic regression model.

The specific scheme was designed as follows:

1) Screening test for significant factors

Not all discrete element simulation model parameters have a significant effect on the repose angle of the fertilizer heap (Xia et al., 2015; Jia et al., 2015). Therefore, factors of significant influence should be screened out first. The Expert Design 12.0 (Xu et al., 2010) was used for the Plackett-Burman test design, so as to obtain the factors which significantly influence the repose angle. Each parameter is expressed as $+1,-1$ or 0 representing the high level, the low level or the central point. There are 13 tests, and the scheme was shown in Table 3.
The results of significant factor screening experiment are shown in Table 7. The results showed that fertilizerfertilizer coefficient of rolling friction, fertilizer-fertilizer coefficient of static friction, and JKR surface energy these three factors had significant influence on angle of repose. The other factors had no on significant impact angle of repose.

2) Single-factor test

After screening out the significant factors (fertilizerfertilizer coefficient of rolling friction, fertilizer-fertilizer coefficient of static friction, and JKR surface energy) using the Plackett-Burman test, a single-factor test was conducted for significant factors in order to explore the influence of significant factors on the repose angle. The test scheme is shown in Table 4, with 5 levels for each significant factor. When the significant factors were taken as constant

Table 3. Test scheme for Plackett-Burman test

\begin{tabular}{|c|c|c|c|c|c|c|c|c|c|c|c|c|}
\hline $\begin{array}{c}\text { Test } \\
\text { serial } \\
\text { number }\end{array}$ & A & B & $\mathrm{C}$ & $\mathrm{D}$ & E & F & G & $\mathrm{H}$ & I & $\mathrm{J}$ & K & $\begin{array}{c}\text { Angle } \\
\text { of } \\
\text { repose } \\
\left({ }^{\circ}\right)\end{array}$ \\
\hline 1 & +1 & +1 & -1 & +1 & +1 & +1 & -1 & -1 & -1 & +1 & -1 & 43.72 \\
\hline 2 & -1 & +1 & +1 & -1 & +1 & +1 & +1 & -1 & -1 & -1 & +1 & 32.79 \\
\hline 3 & +1 & -1 & +1 & +1 & -1 & +1 & +1 & +1 & -1 & -1 & -1 & 27.30 \\
\hline 4 & -1 & +1 & -1 & +1 & +1 & -1 & +1 & +1 & +1 & -1 & -1 & 47.71 \\
\hline 5 & -1 & -1 & +1 & -1 & +1 & +1 & -1 & +1 & +1 & +1 & -1 & 41.80 \\
\hline 6 & -1 & -1 & -1 & +1 & -1 & +1 & +1 & -1 & +1 & +1 & +1 & 31.08 \\
\hline 7 & +1 & -1 & -1 & -1 & +1 & -1 & +1 & +1 & -1 & +1 & +1 & 35.75 \\
\hline 8 & +1 & +1 & -1 & -1 & -1 & +1 & -1 & +1 & +1 & -1 & +1 & 25.47 \\
\hline 9 & +1 & +1 & +1 & -1 & -1 & -1 & +1 & -1 & +1 & +1 & -1 & 25.40 \\
\hline 10 & -1 & +1 & +1 & +1 & -1 & -1 & -1 & +1 & -1 & +1 & +1 & 26.00 \\
\hline 11 & +1 & -1 & +1 & +1 & +1 & -1 & -1 & -1 & +1 & -1 & +1 & 47.15 \\
\hline 12 & -1 & -1 & -1 & -1 & -1 & -1 & -1 & -1 & -1 & -1 & -1 & 19.12 \\
\hline 13 & 0 & 0 & 0 & 0 & 0 & 0 & 0 & 0 & 0 & 0 & 0 & 37.80 \\
\hline
\end{tabular}

$\mathrm{J}$ and $\mathrm{K}$ are for blank columns. 
parameters, the fertilizer-fertilizer coefficient of static friction was set as 0.2 , while the fertilizer-fertilizer coefficient of rolling friction as 0 , and the JKR surface energy as 0 $\mathrm{J} \mathrm{m}^{-2}$. All of the remaining factors without any significant influence on the repose angle were expressed in terms of the median value during the test.

3) The optimal range for significant factors

According to the results of the Plackett-Burman and single factor tests, the effect of significant factors on the repose angle was positive, and the range of the optimal simulation parameters of factors could be determined by the steepest ascent test. The relevant test scheme was as shown in Table 5. The three factors; the fertilizer-fertilizer coefficient of rolling friction, the fertilizer-fertilizer coefficient of static friction and the JKR surface energy, gradually increased with a fixed increment for the steepest ascent test. The relative error was calculated through a comparison with the repose angle in the physical test, and the optimum ranges for the significant factors were determined. All of the remaining factors without the significant influence of the repose angle were expressed in terms of the median value during the test. The relative error $(N, \%)$ was as follows:

$$
N=\frac{|\sigma-\theta|}{\theta} 100 \%,
$$

where: $\sigma$ represents the repose angle of the simulation test ${ }^{\circ}$ ) and $\theta$ represents the repose angle of the actual test.

Table 4. Test scheme for Single factor test

\begin{tabular}{|c|c|c|c|c|c|}
\hline \multirow{2}{*}{$\begin{array}{l}\text { Significance } \\
\text { factor }\end{array}$} & \multicolumn{5}{|c|}{ Level } \\
\hline & 1 & 2 & 3 & 4 & 5 \\
\hline $\begin{array}{l}\text { Fertilizer- } \\
\text { fertilizer } \\
\text { coefficient of } \\
\text { rolling friction }\end{array}$ & 0 & 0.063 & 0.125 & 0.188 & 0.25 \\
\hline $\begin{array}{l}\text { Fertilizer- } \\
\text { fertilizer } \\
\text { coefficient of } \\
\text { static friction }\end{array}$ & 0.2 & 0.4 & 0.6 & 0.8 & 1 \\
\hline $\begin{array}{l}\text { JKR surface } \\
\text { energy }\left(\mathrm{J} \mathrm{m}^{-2}\right)\end{array}$ & 0 & 0.01 & 0.02 & 0.03 & 0.04 \\
\hline
\end{tabular}

4) Response surface optimization test

According to the results of the Plackett-Burman test and the steepest ascent test, the model for the quadratic regression of the three significant factors (fertilizer-fertilizer coefficient of rolling friction, fertilizer-fertilizer coefficient of static friction, JKR surface energy) vs repose angle may be established using the Box-Behnken test, so as to obtain the optimal simulation parameters for the three significant factors. The values at the levels of the Box-Behnken test factors were determined based on the optimal range which in turn was determined by the steepest ascent test, and a high level, a low level and a central point were taken respectively. All of the remaining factors without any significant influence on the repose angle were expressed in terms of the median value during the test. A total of 15 tests were carried out, and the last 3 were for the central point. The test scheme was as shown in Table 6.

\section{RESULTS AND DISCUSSION}

The experiment design and analysis software, Design Expert 12.0 were used to conduct a significance analysis on the results of the screening test (Plackett-Burman test) (Tables 2 and Table 7). The results showed that the fertilizer-fertilizer coefficient of rolling friction $(E)$, fertilizer-fertilizer coefficient of static friction $(D)$, and JKR surface energy $(I)$ had a significant influence on the repose angle of the fertilizer heap $(\mathrm{p}<0.05)$, the degree of influence was as follows; $E>D>I$. Similar results were obtained for the parameter calibration of granular fertilizer (Liu et $a l ., 2018)$. The effect of the fertilizer-fertilizer coefficient of rolling friction on the repose angle of the fertilizer heap was very significant $(p<0.01)$. Due to the spherical shape of the commercial organic fertilizer particles, the rolling friction between the fertilizer particles had an influence which was greater than the static friction in the heaping process of the fertilizer. The collision recovery coefficient between the fertilizer particles was not significant because there was no obvious elastic collision in the formation of the fertilizer heap. Yuan et al. (2018) and Wang et al. (2020) have expressed the relevant research results. Other factors had no significant effect on the repose angle of the fertilizer heap $(p<0.05)$. According to Table 7 , the effects of the three

Table 5. Test scheme for steepest ascent design

\begin{tabular}{cccccc}
\hline $\begin{array}{c}\text { Test } \\
\text { serial } \\
\text { number }\end{array}$ & $\begin{array}{c}\text { Fertilizer-fertilizer } \\
\text { coefficient of rolling } \\
\text { friction }\end{array}$ & $\begin{array}{c}\text { Fertilizer-fertilizer } \\
\text { coefficient of static } \\
\text { friction }\end{array}$ & $\begin{array}{c}\text { JKR surface energy } \\
\left(\mathrm{J} \mathrm{m}^{-2}\right)\end{array}$ & $\begin{array}{c}\text { Simulation test } \\
\text { stacking angle }\left({ }^{\circ}\right)\end{array}$ & Relative error (\%) \\
\hline 1 & 0 & 0.20 & 0 & 19.93 & 37.82 \\
2 & 0.05 & 0.36 & 0.008 & 30.88 & 3.65 \\
3 & 0.10 & 0.52 & 0.016 & 36.02 & 12.39 \\
4 & 0.15 & 0.68 & 0.024 & 39.37 & 22.84 \\
5 & 0.20 & 0.84 & 0.032 & 42.44 & 32.42 \\
6 & 0.25 & 1 & 0.040 & 47.41 & 47.93 \\
\hline
\end{tabular}


factors on the repose angle were all positive, and the repose angle increased with the three factors, the repose Angle and the significant factors of the other bulk organic fertilizers also showed positive effects (Yuan et al., 2018).

An analysis of the single-factor test results (Fig. 8) showed that the repose angle increased along with the three significant factors. The three significant factors were the key to the accuracy of the discrete element simulation of commercial organic fertilizer. In the heaping process of fertilizer, the fertilizer particles at the centre of the fertilizer heap may form a stable heaping state, from which the peripheral fertilizer particles may be expelled and diffuse to the edge. Therefore, the fertilizer particles have a high rotational kinetic energy. In contrast, if the dynamic friction coefficient is small, the inhibitory effect on the rotational inertia of the peripheral particles will also be small, it should be noted that the fertilizer heap is loose, and the repose angle is small. However, if the dynamic friction coefficient is large, the inhibitory effect on the rotational inertia of the peripheral particles will also be large, which is not conducive to the diffusion of the peripheral particles to the edge of the heap, and therefore, the fertilizer will heap to a high point at the centre, thereby producing a larger repose angle. Liu et al. (2018) also described an influence of this sort.

Furthermore, if the static particle-particle friction coefficient is small, the Coulomb friction between the fertilizer particles is also small, and therefore the weight of the fertilizer particles cannot be supported. As a result, the fertilizer particles slide to the edge, it is challenging to form a heap, and thus, the repose angle is small. However, if the static particle-particle friction coefficient is large, the Coulomb friction between the fertilizer particles is also large, in this case, the fertilizer particles can maintain a relatively stable state, thereby forming a stable heap shape, and the repose angle is large. Finally, the JKR surface energy reflects the surface adhesion of the particles, and it also affects the

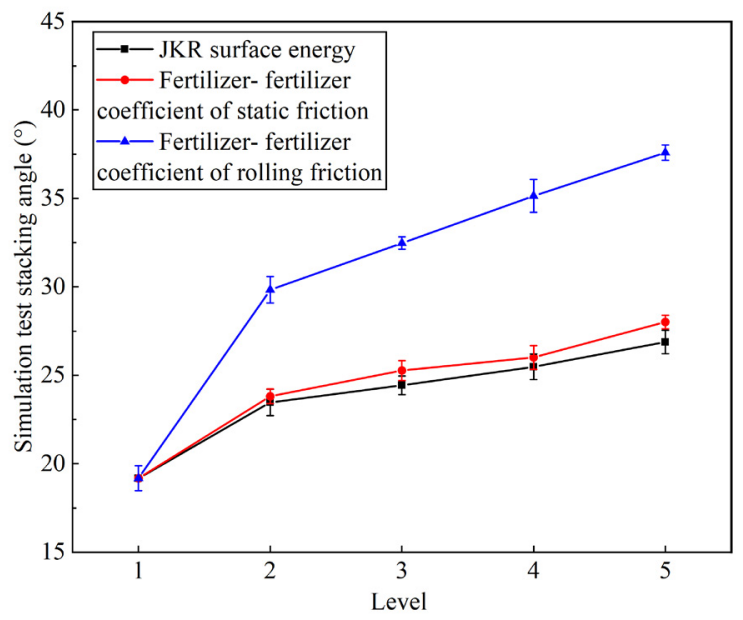

Fig. 8. Effects of various factors on angle of repose. fluidity of the particles. When the JKR surface energy is increased, the particle-particle adhesion increases, and the diffusion of the peripheral particles is inhibited, which is conducive to the formation of a stable heap shape. Moreover, the repose angle increases with the agglomeration of the outer contour. When the JKR surface energy is decreased, the fluidity of the particles is increased, the fertilizer heap is more dispersed, and the repose angle decreases accordingly. Wang et al. (2020) also described this type of influence. Among the three significant factors, the fertilizer-fertilizer coefficient of rolling friction had the most significant influence on the repose angle (Fig. 8).

An analysis based on the steepest ascent test results (Table 5) showed that the repose angle increased with the three significant factors (fertilizer-fertilizer coefficient of rolling friction, fertilizer-fertilizer coefficient of static friction, JKR surface energy) at a gradual rate. Wang et al. (2020) have published their relevant research results. The repose angle error of the simulation test relative to the physical test first decreased and then increased, it then reached a minimum value as the second group of parameters was used for the three significant factors. Therefore, the optimal ranges for the three factors were near the level selected for the second group. In this study, in order to establish the response of the surface model and thereby determine the optimal parameter value, the values of the three factors for the second group of tests were selected as the central point, and the corresponding values for the first group and the third group were assumed to be the low level and the high level respectively (Table 5).

In order to obtain the optimal simulation parameters for the three significant factors, according to the Box-Behnken test results (Table 6), the model for the quadratic regression of the repose angle of the fertilizer particles $v s$ the three factors was established using Design Expert 12.0 software. The quadratic regression equation is as follows:

$\theta=31.05+5.48 E+1.5 D+1.3 I-0.315 D E-0.253 E I$

$-0.423 D I-2.11 E^{2}-0.838 D^{2}-0.276 I^{2}$,

where: $\theta$ is the angle of repose $\left(^{\circ}\right), E$ the fertilizer-fertilizer coefficient of rolling friction, $D$ the fertilizer-fertilizer coefficient of static friction, $I$ the JKR surface energy $\left(\mathrm{J} \mathrm{m}^{-2}\right)$.

An analysis of variance on the Box-Behnken test results were conducted using Design Expert 12.0 software (Table 8 ). The results showed that the model had a high fitting degree $\left(p=1 \times 10^{-4}<0.01, p=0.228>0.05\right.$ for Lack of Fit). The dependent variable (repose angle) and all independent variables were extremely significant, and the failure probability was very small when the model was used for analysis, i.e. the model had a high confidence level. The determination coefficient $\mathrm{R}^{2}=0.991$, calibrated determination coefficient $R_{a d j}{ }^{2}=0.976$, both of which were close to 1 , indicated that the regression model had a good fitting and that the regression equation had a high confidence level. 
Table 6. Test scheme for Box-Behnken test

\begin{tabular}{ccccc}
\hline Test serial number & $\begin{array}{c}\text { Fertilizer- fertilizer } \\
\text { coefficient of rolling } \\
\text { friction }\end{array}$ & $\begin{array}{c}\text { Fertilizer- fertilizer } \\
\text { coefficient of } \\
\text { static friction }\end{array}$ & $\begin{array}{c}\text { JKR surface energy } \\
\left(\mathrm{J} \mathrm{m}^{-2}\right)\end{array}$ & $\begin{array}{c}\text { Simulation test stacking } \\
\text { angle }\left(^{\circ}\right)\end{array}$ \\
\hline 1 & $-1(0)$ & $-1(0.2)$ & $0(0.008)$ & 21.36 \\
2 & $+1(0.1)$ & -1 & 0 & 32.16 \\
3 & -1 & $+1(0.52)$ & 0 & 24.66 \\
4 & +1 & +1 & 0 & 34.20 \\
5 & -1 & $0(0.36)$ & $-1(0)$ & 21.52 \\
6 & +1 & 0 & -1 & 33.77 \\
7 & -1 & 0 & $+1(0.016)$ & 24.05 \\
8 & +1 & 0 & -1 & 35.29 \\
10 & $0(0.05)$ & -1 & -1 & 26.26 \\
11 & 0 & +1 & +1 & 30.43 \\
12 & 0 & -1 & +1 & 30.28 \\
14 & 0 & +1 & 0 & 32.76 \\
15 & 0 & 0 & 0 & 31.09 \\
& 0 & 0 & 0 & 30.58 \\
\end{tabular}

Table 7. Significance analysis of each factor to the angle of repose

\begin{tabular}{|c|c|c|c|c|}
\hline \multicolumn{2}{|l|}{ Factor } & Effect & Mean square & $\mathrm{p}$ - value \\
\hline \multicolumn{2}{|l|}{ Poisson's ratio } & 0.88 & 2.34 & 0.377 \\
\hline \multicolumn{2}{|l|}{ Shear modulus } & -0.35 & 0.37 & 0.699 \\
\hline \multirow{3}{*}{$\begin{array}{l}\text { Fertilizer- } \\
\text { fertilizer } \\
\text { coefficient of }\end{array}$} & restitution & -0.24 & 0.17 & 0.791 \\
\hline & static friction & 6.94 & 144.49 & $0.013 *$ \\
\hline & rolling friction & 15.59 & 729.46 & $0.003^{* *}$ \\
\hline \multirow{3}{*}{$\begin{array}{l}\text { Fertilizer-steel } \\
\text { coefficient of }\end{array}$} & restitution & 0.01 & 0.01 & 0.994 \\
\hline & static friction & -0.37 & 0.42 & 0.681 \\
\hline & rolling friction & 0.96 & 2.76 & 0.345 \\
\hline \multicolumn{2}{|c|}{ JKR surface energy } & 5.82 & 101.62 & $0.018^{*}$ \\
\hline
\end{tabular}

Indicates: significant $* \mathrm{p}<0.05$, very significant $* * \mathrm{p}<0.01$.

The coefficient of variation $C V=2.42 \%$, Adeq Precision $=$ 24.84 , indicated that the model had a high degree of reliability and precision.

In addition, the primary coefficients $E$ (fertilizer-fertilizer coefficient of rolling friction), $D$ (fertilizer-fertilizer coefficient of static friction), and $I$ (JKR surface energy) had a very significant influence on the repose angle $(p>0.01)$, and the degree of influence occurred in the following order: $E>D>I$. The interaction term coefficients $D E, E I$ and $D I$ had no significant influence on the repose angle $(\mathrm{p}>0.05)$. The influence of the interaction term on the repose angle is shown in Fig. 9. The quadratic coefficients, i.e. $E^{2}, D^{2}, I^{2}$, $I^{2}$ had a significant influence on the repose angle $(\mathrm{p}<0.01)$, while the other parameters had no significant influence, thereby indicating the existence of a quadratic relationship between the relevant test factors and response values. The results were generally in agreement with some of the relevant literature (Yuan et al., 2018; Wang et al., 2020).
Under the condition that the model was significant and the mismatch term was not significant, the term that had no significant effect on the result was removed and the regression model was simplified. The new regression equation was as following:

$\theta=30.88+5.48 E+1.5 D+1.3 I-0.423 D I-2.09 E^{2}-0.817 D^{2}$.

The variance analysis of the simplified regression model was shown in Table 9. Coefficient of variation of the simplified model was reduced to $2.24 \%$, and the reliability of the model was further increased; the coefficient of correction determination $R_{a d j}{ }^{2}=0.980$, which indicated that the model had high fitting degree; Adeq Precision $=32.50$, which was higher than that before simplification.

In order to obtain the optimal simulation parameters for the three significant factors, i.e. $E$ (fertilizer-fertilizer coefficient of rolling friction), $D$ (fertilizer-fertilizer coefficient of static friction), and $I$ (JKR surface energy), Design 
Table 8. Results of variance analysis of response surface model

\begin{tabular}{crrrr}
\hline Source & $\begin{array}{r}\text { Sum of } \\
\text { squares }\end{array}$ & df & $\begin{array}{r}\text { Mean } \\
\text { square }\end{array}$ & p - value \\
\hline Model & 291.2 & 9 & 32.35 & $1 \times 10^{-4 * *}$ \\
$E$ & 240.1 & 1 & 240.1 & $1 \times 10^{-4 * *}$ \\
$D$ & 17.97 & 1 & 17.97 & $0.002 * *$ \\
$I$ & 13.52 & 1 & 13.52 & $0.004 * *$ \\
$D E$ & 0.40 & 1 & 0.40 & 0.415 \\
$E I$ & 0.26 & 1 & 0.26 & 0.508 \\
$D I$ & 0.71 & 1 & 0.71 & 0.287 \\
$E^{2}$ & 16.49 & 1 & 16.49 & $0.002 * *$ \\
$D^{2}$ & 2.59 & 1 & 2.59 & 0.072 \\
$I^{2}$ & 0.28 & 1 & 0.28 & 0.489 \\
Residual & 2.51 & 5 & 0.50 & \\
Lack of Fit & 2.12 & 3 & 0.70 & 0.228 \\
Pure Error & 0.40 & 2 & 0.20 & \\
Cor Total & 293.7 & 14 & & \\
$\mathrm{R}^{2}=0.991, R_{a d j}{ }^{2}=$ & $0.976, C V=2.42 \%$, Adeq Precision $=24.84$ \\
\hline
\end{tabular}

Explanations as in Table 7.

Expert 12.0 software was used to optimize the established quadratic regression model by $32.05^{\circ}$, a measured repose angle in the physical test, as the target. A mathematical model for the optimization solution was established using the range of parameters in Table 5 as a boundary:

$$
\text { Objective function: } X=(E, D, I)=32.05^{\circ}
$$

$$
\text { Constraint conditions: }\left\{\begin{array}{c}
f_{1}=E \geq 0 \\
f_{2}=0.1-E \geq 0 \\
f_{3}=D-0.2 \geq 0 \\
\mathrm{f}_{4}=0.52-\mathrm{D} \geq 0 \\
\mathrm{f}_{5}=\mathrm{I} \geq 0 \\
f_{6}=0.016-I \geq 0,
\end{array}\right.
$$

where: $f_{1} \sim f_{6}$ represents the horizontal range of factors $E, D$ and $I$, while $X$ represents the angle of repose.
Table 9. Analysis of variance of simplified model

\begin{tabular}{crrrl}
\hline Source & $\begin{array}{r}\text { Sum of } \\
\text { squares }\end{array}$ & df & $\begin{array}{c}\text { Mean } \\
\text { square }\end{array}$ & $\mathrm{p}$ - value \\
\hline Model & 290.3 & 6 & 48.38 & $1 \times 10^{-4 * *}$ \\
$E$ & 240.1 & 1 & 240.1 & $1 \times 10^{-4 * *}$ \\
$D$ & 17.97 & 1 & 17.97 & $2 \times 10^{-4 * *}$ \\
$I$ & 13.52 & 1 & 13.52 & $5 \times 10^{-4 * *}$ \\
$D I$ & 0.71 & 1 & 0.71 & 0.234 \\
$E^{2}$ & 16.26 & 1 & 16.26 & $3 \times 10^{-4 * *}$ \\
$D^{2}$ & 2.48 & 1 & 2.48 & $0.043^{*}$ \\
Residual & 3.45 & 8 & 0.43 & \\
Lack of Fit & 3.05 & 6 & 0.51 & 0.309 \\
Pure Error & 0.40 & 2 & 0.20 & \\
Cor Total & 293.7 & 14 & & \\
$\mathrm{R}^{2}=0.988, R_{a d j}{ }^{2}=$ & $0.980, C V=$ & $2.24 \%$, Adeq Precision $=32.50$ \\
\hline
\end{tabular}

Explanations as in Table 7.

According to the multiple optimal solutions obtained after optimization, the group of values closest to the actual repose angle was obtained through validating each set of data: the fertilizer-fertilizer coefficient of rolling friction was 0.056 , the fertilizer-fertilizer coefficient of static friction was 0.355 , and the JKR surface energy was $0.011 \mathrm{~J}$ $\mathrm{m}^{-2}$. Due to the differences in moisture and chemical composition, the calibration results of the commercial organic fertilizer model are much different from those of other fertilizer model parameters calibrated by Yuan et al. (2018), Liu et al. (2018) and Luo et al. (2018). In order to further verify the validity and error of the calibrated parameters, the optimal values of the significant factors and the median values of other non-significant factors (Table 2) were used for the simulation verification test in this study. The repose angles of the 5 repeated tests were $32.48,32.31,31.81,31.34$ and $32.97^{\circ}$, respectively, with an average value of: $32.18^{\circ}$. A comparative analysis between the simulation verification test and the physical test showed that (Fig. 10) the error in the repose angle obtained using the optimal simulation parameter relative to that obtained in the physical test was

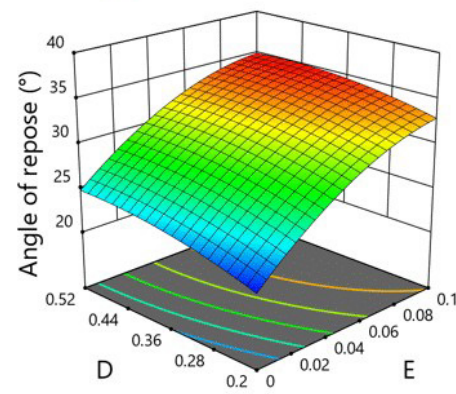

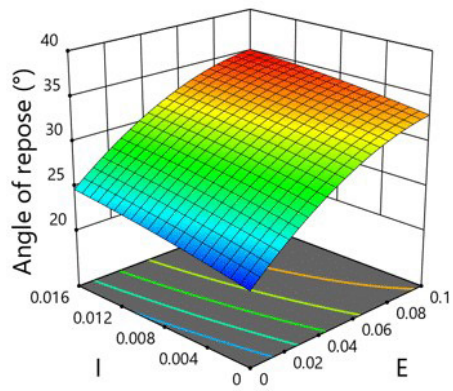

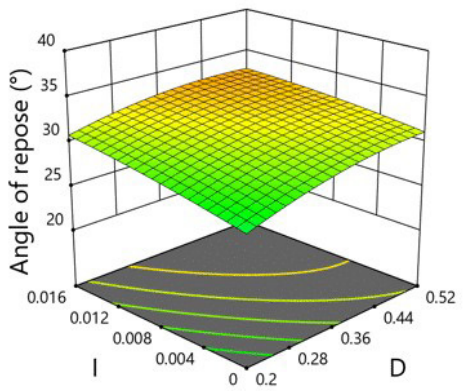

Fig. 9. Influence of significant factor interaction term on angle of repose interaction effect diagram of: $\mathrm{a}-D E, \mathrm{~b}-E I, \mathrm{c}-D I$. 


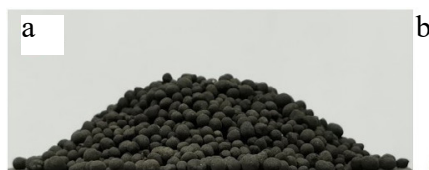

b

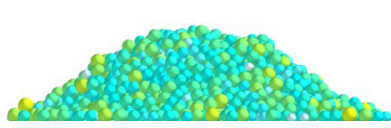

Fig. 10. Comparison between the physical test and simulation test: $\mathrm{a}$ - physical test, $\mathrm{b}$ - simulation test.

only $0.40 \%$, and there was no significant difference in the shape of the fertilizer heap. In this paper, spherical granular commercial organic fertilizer which is widely used in the process of agricultural machinery fertilization was selected as the research object. The results of this study can provide a reference for the discrete element simulation of spherical like commercial organic fertilizer, and provide basic parameters for establishing a discrete element model for commercial organic fertilizer particles, and also evaluating the performance of organic fertilizer feeders. In addition, the material characteristic parameters of other commercial organic fertilizers could be calibrated with reference to the research method in this paper.

\section{CONCLUSIONS}

Based on the combination of the physical test and simulation test, with the repose angle set as the response index, EDEM software was used to construct a discrete element simulation model of commercial organic fertilizer particles, and also to calibrate the relevant parameters. The conclusions are as follows:

1. Significance factor screening test results showed that among the parameters for the simulation model, only three parameters, namely, the fertilizer-fertilizer coefficient of rolling friction, the fertilizer-fertilizer coefficient of static friction and the Johnson-Kendall-Roberts surface energy, had a significant influence over the repose angle $(\mathrm{p}<0.05)$, while the other parameters had no significant influence over the repose angle ( $p>0.05)$. The single factor simulation test showed that the repose angle increased with the three significant parameters, and that the dynamic particle-particle friction coefficient had the most significant influence over the repose angle. The degree of influence of the three parameters occurred in the following order: $E>D>I$.

2 . The response surface optimization test results showed that the interaction terms of the three parameters had no influence over the response index (repose angle) $(p<0.05)$, the quadratic term of the dynamic particle-particle friction coefficient had a significant influence over the repose angle $(p<0.05)$, and the quadratic terms of the other parameters had no significant influence over the repose angle ( $p>0.05)$. Through the creation and solution of the quadratic regression model, the optimal simulation parameters obtained were as follows: the fertilizer-fertilizer coefficient of rolling friction $=0.056$, the fertilizer-fertilizer coefficient of static friction $=0.355$, and the Johnson-Kendall-Roberts surface energy $=0.011 \mathrm{~J} \mathrm{~m}^{-2}$.
3. The discrete element simulation test was carried out with the optimal simulation parameters. The error of the repose angle in the simulation test relative to that in the physical test was $0.40 \%$, which indicated the accuracy and effectiveness of the simulation parameters for the discrete element model of the organic fertilizer. The calibration results of the simulation parameters may provide the basic parameters for the creation of a discrete element model of commercial organic fertilizer particles for the purpose of evaluating the performance of organic fertilizer feeders.

Conflict of interest: The authors declare no conflict of interest.

\section{REFERENCES}

Chen Y., Munkholm L.J., and Nyord T., 2013. A discrete element model for soil-sweep interaction in three different soils. Soil Till. Res., 126: 34-41. https://doi.org/10.1016/j. still.2012.08.008

Coetzee C.J., and Els D.N.J., 2009. Calibration of discrete element parameters and the modelling of silo discharge and bucket filling. Computers Electronics Agric., 65(2): 198212. https://doi.org/10.1016/j.compag.2008.10.002

Dong X.Y. and Yao W.C., 2010. Basic situation of organic fertilizer and its position in agricultural production. Modern Agric., (08): 30-31.

Fadavi A., Mirzabe A.H., and Mansouri A., 2015. Moisturedependent physical properties of Plantain (Plantago major L.) seeds by image processing analysis. Agric. Eng. Int.: CIGR J., 17(3): 353-363.

Fielke J.M., Ucgul M., and Saunders C., 2013. Discrete element modeling of soil-implement interaction considering soil plasticity, cohesion and adhesion. ASABE Int. Meeting, July 21-24, Kansas City, USA.

Gallego E., Fuentes J.M., Ruiz Á., Hernández-Rodrigo G., Aguado P., and Ayuga F., 2020. Determination of mechanical properties for wood pellets used in DEM simulations. Int. Agrophys., 34(4), 485-494. https://doi.org/10.31545/ intagr/130634

Ghazavi M., Hosseini M., and Mollanouri M., 2008. A comparison between angle of repose and friction angle of sand. 12th Int. Conf. Int. Association for Computer Methods and Advances in Geomechanics (IACMAG), October 1-6, Goa, India.

González-Montellano C., Fuentes J.M., Ayuga-téllez E., and Ayuga F., 2012. Determination of the mechanical properties of maizegrains and olives required for use in DEM simulations. J. Food Eng., 111(4): 553-562. https://doi. org/10.1016/j.jfoodeng.2012.03.017

Han Y.L., Jia F.G., Tang Y.R., Liu Y., and Zhang Q., 2014. Influence of granular coefficient of rolling friction on accumulation characteristics. Acta Physica Sinica, 63(17): 173-179. https://doi.org/10.7498/aps.63.174501

Hu Y.G., Yang Y.C., Xiao H.R., and Li P.P., 2016. Simulation and parameter optimization of centrifugal fertilizer spreader for tea plants. Trans. Chinese Soc. Agric. Machinery, 47(05): 77-82. 
Huang S.W., Tang J.W., and Li C.H., 2017. Status of heavy metals, nutrients, and total salts in commercial organic fertilizers and organic wastes in China. J. Plant Nutr. Fertil., 23(1): 162-173.

Huang Y.X., Hang C.G., Yuan M.C., Wang B.T., and Zhu R.X., 2016. Discrete element simulation and experiment on disturbance behavior of subsoiling. Trans. Chinese Soc. Agric. Machinery, 47(07): 80-88.

Jia X.G., Chen X., and Li X., 2015. Experiment research on instantaneous natural repose angle of granular slope under different granularity and stack form. Modern Mining, 31(01): 25-27+45.

Jiang Q., Wang R.B., and Sun W.L., 2018. Potential evaluation and countermeasures on livestock manure resource utilization-based on perspective of commercial organic fertilizer utilization. J. Huazhong Agric. University (Social Sciences Edition), 30-37, 166-167.

Li B., Chen Y., and Chen J., 2016. Modeling of soil-claw interaction using the discrete element method (DEM). Soil Till. Res., 158: 177-185.

Liu C.L., Wei D., Song J.N., Li Y.N., Du X., and Zhang F.Y., 2018. Systematic study on boundary parameters of discrete element simulation of granular fertilizer. Trans. Chinese Soc. Agric. Machinery, 49(09): 82-89.

Liu F.Y., Zhang J., and Chen J., 2018. Construction of viscoelasto-plasticity contact model of vibratory screening and its parameters calibration for wheat. Trans. Chinese Soc. Agric. Eng., 34(15): 37-43.

https://doi.org/10.1016/j.still.2015.12.010

Liu F.Y., Zhang J., Li B., and Chen J., 2016. Calibration of parameters of wheat required in discrete element method simulation based on repose angle of particle heap. Trans. Chinese Soc. Agric. Eng., 32(12): 247-253.

Luo S., Yuan Q.X., Gouda S., and Yang L.Y., 2018. Parameters calibration of vermicomposting nursery substrate with discrete element method based on JKR contact model. Trans. Chinese Soc. Agric. Machinery, 49(04): 343-350.
Molenda M., Horabik J., Lukaszuk J., and Wiącek J., 2011. Variability of intergranular friction and its role in DEM simulation of direct shear of an assembly of rapeseeds. Int. Agrophys., 25(4), 361-368.

Oleh B., Alfred D., Enrique R., and Allen W., 2009. Simulation of a schulze ring shear tester. Proc. 6th Int. Conf. Micromechanics of Granular Media, July 01, 1145, 409.

Ucgul M., Fielke J.M., and Saunders C., 2015. Threedimensional discrete element modelling (DEM) of tillage: accounting for soil cohesion and adhesion. Biosys. Eng., 129: 298-306. https://doi.org/10.1016/j.biosystemseng.2014.11.006

Wang L.M., Fan S.Y., Cheng H.S., Meng H.B., Sheng Y.J., Wang J., and Zhou H.B., 2020. Calibration of contact parameters for pig manure based on EDEM. Trans. Chinese Soc. Agric. Eng., 36(15):95-102.

Wang X.L., Hu H., Wang Q.J., Li H.W., He J., and Chen W.Z., 2017. Calibration method of soil contact characteristic parameters based on DEM theory. Trans. Chinese Soc. Agric. Machinery, 48(12): 78-85.

Xia P., Li Y., and Yang G.B., 2015. Discrete element simulation study on pile angle of bulk material. Hoisting and Conveying Machinery, (02): 107-110.

Xu X.H. and He M.Z., 2010. Experimental design and application of design-expert and SPSS. Science Press, Beijing, China.

Zhao Y.Z., Jiang M.Q., Xu P., and Zheng J.Y., 2009. Discrete element simulation of the microscopic mechanical structure in sandpile. Acta Physica Sinica, 58(03): 1819-1825. https://doi.org/10.7498/aps.58.1819

Zhang X.M., 2017. Study on the drying process and equipment for organic fertilizer pellets. China Agricultural University, Beijing, China.

Zhong W.Z., He K.J., Zhou Z.Y., Xia W., and Li Y.Y., 2009. Calibration of damping coefficient in discrete element method simulation. Acta Physica Sinica, 58(08): 51555161. https://doi.org/10.7498/aps.58.5155 